\title{
Direct and indirect impacts of the COVID-19 pandemic on women and girls
}

\author{
Luke Kelly \\ University of Manchester
}

13 August 2021

\section{Question}

What are the direct and indirect impacts of the COVID-19 pandemic on women and girls, and gender equality progress?

Have the impacts have been disproportionate on women and girls (as opposed to men and boys)?

How have the impacts of COVID-19 on women and girls have varied according to age, income, disability, ethnicity and other factor?

In answering the question, the researcher will focus on our areas of interest, which are the impact of COVID-19 on:

- $\quad$ Girls' access to education

- $\quad$ Gender roles in the care economy, including unpaid care

- Women's access to capital, job markets, and business ownership

- Women's access to global trade

- $\quad$ Gender equality in STEM education and careers

- $\quad$ The digital gender divide, access to internet, and algorithmic bias

- Violence against women and girls, including the 'shadow pandemic' of domestic violence, and FGM.

- $\quad$ Online harassment and abuse of women and girls

- $\quad$ Conflict-related sexual violence and response to it

- [Climate change and participation in the green economy] (if there is sufficient evidence of COVID-19 impacts)

- $\quad$ [Gender stereotyping the media] (if there is sufficient evidence of COVID-19 impacts)

The K4D helpdesk service provides brief summaries of current research, evidence, and lessons learned. Helpdesk reports are not rigorous or systematic reviews; they are intended to provide an introduction to the most important evidence related to a research question. They draw on a rapid desk-based review of published literature and consultation with subject specialists. 
The report will focus on the contexts of G7 countries and ODA-eligible countries.

\section{Contents}

1. Summary

2. Impact on women and girls

5. References 


\section{Summary}

This rapid literature review finds that women have been disproportionately affected by Covid-19 in several ways. As the Covid-19 pandemic began, it was widely predicted that women would face worse outcomes than men in many spheres. This was based on evidence of pre-existing inequalities (e.g. the high share of women in informal work) and evidence from earlier disease outbreaks such as Ebola.

Evidence from the past year and a half supports the idea that women have been disproportionately affected by Covid-19 in many of the issues investigated for this report. A wideranging World Bank review of evidence from April 2020 to April 2021 states that "women often appear to have lost out more than men economically and socially" (Nieves et al., 2021, p. 4). It was not possible to find evidence on the effect of Covid-19 on women's role in the green economy and the effects of climate change (beyond calls for inclusive green growth), or on gender stereotyping in the media (although there is a small amount of literature on perceptions of women leaders during the pandemic).

In all cases, the effect of Covid-19 and measures to suppress it have directly or indirectly continued or worsened pre-existing inequalities. In some instances, Covid-19 has created distinct difficulties for women (e.g. lockdowns and increased domestic violence). This report has found no evidence of Covid-19 improving the position of women in the areas of interest surveyed, beyond possible benefits from working from home for some women in high-income countries; and some suggestions that female leadership during the pandemic may lead to better perceptions of women (Piazza \& Diaz, 2020). Studies also point to the intersection of gender with other factors, such as caste and ethnicity, leading to worse outcomes (Chen et al., 2021; Kabeer et al., 2021). In many cases, migrant women and women with disabilities are at an increased disadvantage.

The report focuses on evidence from low- and middle-income countries (LMICs) and G7 members. It is not comprehensive but surveys the available evidence focusing on global, regional or synthesis evidence to provide a more representative coverage. It, therefore, does not cover every context or provide any country case studies and overlooks variations in some countries in favour of broader trends.

\section{Impact on women and girls}

\section{Girls' access to education}

Globally, around 1.6 billion children have not been in school due to the pandemic. Furthermore, "it has been projected that around 11 million girls will not return to school when the crisis is over, especially in low-and lower-middle income countries. Girls aged 12-17 are at particular risk of dropping out permanently as a result of the pandemic" (Nieves et al., 2021, p. 11).

Evidence from previous disease outbreaks or crises suggests several pathways by which girls' education is disrupted, including: being burdened with extra household work and childcare; loss of household income creating a need for extra paid work; early marriage; early pregnancy; disrupted access to safe spaces; disrupted access to health services; and greater threat of 
sexual- and gender-based violence (Acosta \& Evans, 2020). Many of these indirect effects of crisis can make it harder for girls to attend school or learn remotely.

There is not yet conclusive evidence on gender gaps in education caused by Covid-19. A World Bank working paper does not find evidence that boys have been prioritised over girls in education (Nieves et al., 2021, p. 11). Gender gaps differ according to region and level of education, and there is no overall statistically significant trend (Nieves et al., 2021, p. 11). UNESCO projections suggest that "boys are at a greater risk of not returning to education than girls at university, primary and lower-secondary school, while the opposite holds for pre-primary and upper secondary education". Girls are less likely to return to schooling in Sub-Saharan Africa, however (Nieves et al., 2021, p. 11).

There is not enough data on gender gaps in remote learning. Data from some countries (Bangladesh and the DRC, for instance) shows better access to the internet for boys than girls. However, studies show slightly higher levels of engagement for girls than boys in other countries, although often not to a statistically significant degree (Nieves et al., 2021, p. 11).

There is evidence of girls taking on a heavier burden of caring and household responsibilities (Nieves et al., 2021). More girls have reported an increase in household chores than boys in a Save the Children survey of 46 countries. Other surveys report similar results (Nieves et al., 2021 , p. 12). This is likely to have an impact on girls' schooling.

\section{Gender roles in the care economy}

Existing trends mean that the increased burden of care from Covid-19 was likely to fall disproportionately on women and girls. "Social norms in almost every country assign care and other unpaid work overwhelmingly to women" (Nieves et al., 2021, p. 18). Care workers are disproportionately female, with women making up $70 \%$ of workers in healthcare and social services (Kabeer et al., 2021, p. 10).

The evidence suggests that increased paid and unpaid care work because of Covid-19 has fallen disproportionately on women and girls. Data from several countries shows women were more likely to stop paid work or reduce their hours to look after their children or elderly relatives during Covid-19 (Kabeer et al., 2021, p. 14). Some evidence from across the world has found that men are contributing more to household work since the pandemic, but they still contribute less than women and girls (Nieves et al., 2021, p. 19). Overall, "women were more likely than men to stop working and have borne the brunt of the increase in the demand for care work" (Nieves et al., 2021, p. 2).

Care workers are at higher risk of catching Covid-19 because of their close proximity to patients and, in some cases, lack of personal protective equipment (ILO, 2021, p. 99). Care centres have had high rates of Covid-19. In some cases, they have had less access to personal protective equipment (PPE) (e.g. the UK, where the death rate for care workers was twice that of healthcare staff) (Foley and Piper, 2020, p. 5).

Extra caring responsibilities are also likely to reduce women's paid employment opportunities as they have taken on more unpaid care work because of Covid cases and school closures. Many women experience a 'double burden', where increased paid care work is supplemented by increased unpaid care work as schools close or relatives fall ill with Covid. 
Many experienced increased work at home because school closures meant they needed to spend more time caring for children (Foley and Piper, 2020, p. 5). However, there are some exceptions and women are less likely to take on extra caring responsibilities because of Covid-19 "in rural, agrarian contexts, where most people work on family farms and in other household enterprises, and where it is more common to combine economic activity with care for young children" (Nieves et al., 2021, p. 14).

Migrant face particular risks. They are overrepresented in the care sector. Migrant domestic workers are now more at risk of insecurity, violence and deportation. Many are being dismissed because of Covid-19 but unable to return to their countries of origin or work elsewhere (Foley and Piper, 2020, p. 6). Opportunities to leave their workplaces have been reduced by Covid, putting them at greater risk of violence by employers (Foley and Piper, 2020, p. 6). Those who work informally risk fines or deportation, especially if they travel between workplaces at times of restrictions on movement (Foley and Piper, 2020, p. 6).

\title{
Women's access to capital, job markets and business ownership
}

\begin{abstract}
A World Bank working paper summarising evidence on gender over the course of the pandemic shows that women have experienced more negative economic effects than men. Gender differences are more significant than age, education or rural/urban locality (Nieves et al., 2021). The journal Feminist Economics summarises the available evidence. It shows a disproportionate impact on women in the form of more job losses in female-dominated sectors, as well as more women working in frontline jobs with higher risks of Covid-19 (Kabeer et al., 2021).
\end{abstract}

Overall figures show that more women have lost jobs or income. The International Labour Organization shows that unemployment losses were $5 \%$ for women and $3.9 \%$ for men globally in 2020. In all regions, more women have become economically inactive (ILO, 2021, p. 9). Informal workers have been hit particularly hard by lockdowns, and women have tended to suffer disproportionately (Chen et al., 2021).

There are several reasons for this gap, which may apply more or less in different contexts. These include the concentration of women in sectors affected by lockdown, such as hospitality, or in informal work (ILO, 2021). Between April and June 2020, 36\% of women compared to $28 \%$ of men stopped working (from a survey of 40 mostly developing countries) (Nieves et al., 2021, p. 14). This is partly the result of sectoral segregation (although the effect has not been fully quantified). For example, in Latin America and the Caribbean, gender differences are explained by the heavy job-losses in female-dominated sectors such as trade, personal services, education and hospitality (Nieves et al., 2021). In the informal sector, women's jobs are more protected than men's, but with a drop in working hours and evidence of greater falls in income, according to ILO forecasts (O'Donnell et al., 2021, p. 14).

The pace of recovery since the second half of 2020 also appears to have been slower for women than men (Nieves et al., 2021). Evidence from Kenya, Ghana and China in late 2020 finds that female farmers have not begun to recover as much as male farmers (O'Donnell et al., 2021, p. 15).

Women-led businesses were also more likely to close due to Covid-19 (O'Donnell et al., 2021, p. 11). They are also less likely to have received public support (Nieves et al., 2021). For 
example, in every region of the world, rates of business closure for small- and micro-firms were higher for female businesses (O'Donnell et al., 2021, p. 11). Table 1 shows a greater rate of closure for female-led businesses. The sample was taken between January and June 2002 from a survey of 26,948 businesses using Facebook in 50 countries.

Table 1: Gender Gap in Micro and Small Firm Business Closures across regions, from a Facebook COVID-19 Future of Business Survey

\begin{tabular}{lll}
\hline Region & $\begin{array}{l}\text { Female business closure } \\
\text { rate }(\%)\end{array}$ & $\begin{array}{l}\text { Male business closure rate } \\
(\%)\end{array}$ \\
\hline Sub-Saharan Africa & 41 & 34 \\
\hline Latin America & 40 & 29 \\
\hline North America & 31 & 17 \\
\hline MENA & 28 & 22 \\
\hline Europe & 23 & 17 \\
\hline Asia and Oceania & 22 & 16 \\
\hline
\end{tabular}

Source: (Copley et al., 2020, p. 2) reproduced under CC BY 3.0 IGO

Some workers have been particularly affected by pandemic restrictions. Migrant women sex workers are unable to work because of movement restrictions. They are also often unable to access healthcare or social protection because of barriers related to their migrant status. Their health may also be compromised - if they continue to work, they are at greater risk of catching Covid-19, and public information on Covid-19 protection may not be written in a language they know (Foley and Piper, 2020, p. 7).

\section{Women's access to global trade}

Disruption to international trade has affected female-intensive sectors worse. International and regional trade and value chains have been negatively affected by Covid-19. This has led to job losses, particularly focused on women in female-dominated industries such as garment factories in Asia and the Pacific (Barrientos \& Pallangyo, 2020, p. 126; O'Donnell et al., 2021, p. 14; WTO, 2020). Both US demand shocks and Chinese manufacturing contractions hit femaleintensive sectors more than others (Barrientos \& Pallangyo, 2020).

For example, women make up $60 \%-80 \%$ of the global clothing workforce and low-income countries hosting a lot of garment factories such as Bangladesh or Vietnam have been hit hard by Covid's effect on the garment trade. As of August 2020, it was estimated that 1 million garment workers in Bangladesh had been dismissed or furloughed (WTO, 2020). Women also make up more than half of workers in the travel and tourism industry, which have been significantly affected by global travel restrictions (WTO, 2020).

In many contexts, a shift away from cash crops to subsistence farming has occurred. A study in India found that increases in the cost of agricultural inputs and reduced access to markets have 
causes this. $27 \%$ of women farmers surveyed in India and $29 \%$ in Nepal "reported their regular source of extension services was unavailable during lockdowns" (O'Donnell et al., 2021, p. 15)

\section{Women in science, technology, engineering and medicine (STEM)}

Girls are underrepresented in STEM subjects in school, as are women in the STEM workforce (Sanchez-Tapia \& Alam, 2020). The disruptions to education brought about by Covid19 mean this is not likely to improve (Woolston, 2020).

Evidence suggests that the pressures of the pandemic on STEM workers are negatively affecting underrepresented and marginalised groups such as women. Among 4,535 research scientists surveyed in Europe and the US, women experienced a 5\% larger decline in research time because of Covid-19 (UNESCO, 2021). Those with children under five years old saw a $17 \%$ decline in their research time. Studies also suggest that women scientists' publishing rate has fallen during the pandemic (UNESCO, 2021). Surveys of STEM researchers in the AsiaPacific region also show that gender inequality has been exacerbated, for a number of reasons, including that women are more likely to be precariously employed, be burdened by additional domestic work and other issues (Australian Academy of Science, 2021)

The pandemic has also been seen as an opportunity to amplify the contribution of female scientists at a time of heightened public interest in science (UNESCO, 2021). Many of the leading scientists behind vaccines have been women, for example. However, male scientists have been given more time in the media than female scientists on Covid issues (UNESCO, 2021). A big data analysis of 146,867 articles on Covid in the UK, US and Australia between March and July 2020 found that male STEM experts were mentioned nineteen times more often than female STEM experts (Jones, 2020). An international analysis of 1.9 million news stories in India, Kenya, Nigeria, South Africa, the UK and the US between March and April 2020 found that the ratio of men to women who were quoted as experts, sources or protagonists in news stories was $73 \%$ men to $25 \%$ women in the UK; $73 \%$ men to $20 \%$ women in Kenya; $78 \%$ men to $19 \%$ women in the US; $77 \%$ men to $17 \%$ women in South Africa; $81 \%$ men to $17 \%$ women in Nigeria; and $82 \%$ men to $16 \%$ women in India (Kassova, 2021). ${ }^{1}$

In addition, some women have been able to benefit from shorter working hours or working at home, although less so than men, as their share of childcare and household chores is greater (The Impact of COVID-19 on Women Scientists from Developing Countries: Results from an OWSD Member Survey / OWSD, n.d.)

\section{Digital divide}

Lockdowns and school closures mean much education has shifted to being delivered online, through radio or through television. However, this has highlighted the 'digital divide' between those with access to digital technologies and those without (Sanchez-Tapia \& Alam, 2020). In many countries, there is a gendered digital divide, with girls having less access to the internet and lower levels of digital literacy (Amaro et al., 2020).

${ }^{1}$ Totals do not add up to $100 \%$ because some quoted have not been identified as men or women. 
In the context of Covid-19, there is evidence that boys are often prioritised over girls in access to remote learning technology in some contexts (Marshall \& Moore, 2020). Parents often fear that girls may be at risk online, and parental concerns about the safety of the internet may have led to a drop in girls' use of remote learning in Palestine, for example (Crompton, Helen et al., 2021). However, the overall evidence is not conclusive (Nieves et al, 2021, p. 11).

The digital divide is structured by wealth and rural/urban differences, as well as gender. In India, there is evidence that rural girls have less access to digital technology than rural boys and that urban girls have less access to technology than urban boys (Marshall \& Moore, 2020). Women in developing countries are concentrated in lower-earning jobs that are less likely to be 'telecommutable', and may have limited IT skills to access online opportunities (WTO, 2020).

\section{Violence against women and girls}

It has been found that the risk of VAWG has increased because of the pandemic (Nieves et al., 2021). Suggested causes of increased VAWG include increased stress, quarantines and isolation, breakdown in social infrastructure, family separation in conflict areas, reduced access to services (Nieves et al., 2021). Some groups are likely to be affected worse. Women with disabilities suffer higher rates of violence than women without disabilities (UN Women, 2021b).

Covid-19 has disrupted the mechanisms for measuring VAWG. Calls to helplines can be an unreliable measure, and health surveys were paused during Covid in many countries.

Administrative reports by service providers, e.g. police statistics, vary in quality. In the Center for Global Development's (CGD's) most recent review - April 2021 - of studies on VAWG during Covid, more studies are using survey data rather than hotline calls or administrative reports. Some studies also use 'Big Data', e.g. internet searches and GPS tracking (Bourgault et al., 2021).

Despite limitations to the available data, evidence collected since the pandemic began supports the view that VAWG has increased due to Covid-19. Findings from various studies globally are based on increased calls to helplines across various countries, increases in femicides in several countries, increased reports of attacks on female healthcare workers, as well as the closure of services such as shelters for survivors of gender-based violence (Nieves et al., 2021).

The CGD's analysis of the evidence on VAWG during the pandemic finds evidence of increases in papers using a range of methodologies. 12 of the 15 of the papers surveyed (between December 2020 and March 2021, covering a range of states) show an increase in VAWG (Bourgault et al., 2021). Risk factors identified included unemployment, lost income due to the pandemic and substance abuse by the perpetrator (Bourgault et al., 2021).

Covid-19 has also disrupted services for victims of violence. UNICEF's assessment of the effects of Covid-19 between May and August 2020 found that the majority of respondents in every region except East Asia and the Pacific reported disruption to services addressing violence against children (UNICEF, 2020). Evidence gathered by UN Women finds that in many countries, "physical distancing and shelter-in-place orders, have disrupted the availability of, and accessibility to, services for survivors of violence" (Pacardo, 2020, p. 4). 
Women from marginalised groups may face more barriers to service provision. For example, "it is reported that women with disabilities and elderly women who have recovered from COVID-19 are stigmatised and isolated from the support of their communities." (Pacardo, 2020, p. 3). In "Kenya, Rwanda, South Africa, Uganda, and Zimbabwe, there are reported incidents of denied access to services for women migrant workers returning home from other countries" (Pacardo, 2020, p. 3).

There is limited data on the issue, but it is estimated that Covid conditions have led to an increased risk of child marriage - UNICEF puts this at 10 million more girls at risk (Nieves et al., 2021, p. 28). This is because of disruption to education, loss of livelihoods, economic insecurity etc. Covid-19 is delaying or stopping VAWG prevention programmes. "UNFPA analysis reports that a 2-year delay in initiating prevention programmes is projected to lead to an additional 13 million child marriages, as well as 2 million female genital mutilation cases over the next decade that otherwise would have been averted, that is, a $33 \%$ reduction in progress" (Meagher et al., 2020).

\section{Online harassment and abuse}

Increased internet use means cases of online abuse of women have been documented following changes to working habits during the pandemic (UN Women, 2020). Lockdown measures have lead to increases in internet use of $50 \%$ to $70 \%$. Women were already subject to disproportionate internet abuse before the pandemic, which reports and studies suggest has increased, or is likely to increase since Covid-19 (Strenio \& Chowdhury, 2021; UN Women, 2020).

For example:

- A 50\% increase in online abuse and bullying has been reported in Australia (UN Women, 2020).

- A UK survey points to an upsurge of online harassment of women who are working at home during Covid restrictions ('Rights of Women Survey Reveals Online Sexual Harassment Has Increased, as Women Continue to Suffer Sexual Harassment Whilst Working through the Covid-19 Pandemic.', 2021). 23\% who experienced harassment reported an increase since the start of lockdown. The findings come from a survey conducted by Rights of Women in November-December 2020.

\section{Conflict-related violence}

Women also experience a double burden in conflict- and Covid-affected contexts. SGBV typically increases during conflict and humanitarian crises. While "it is challenging to obtain SGBV data in conflict settings during COVID-19, and it is widely under-reported", rises were reported during the Ebola outbreak in 2013-15. Increases can be due to "suspension of these protection services for women, restrictions on mobility, lack of information and increased isolation" (Meagher et al., 2020)

Efforts to include women more in peacebuilding efforts appear to have stalled in some contexts. Women in peace and security (WPS), which is widely seen as an effective measure, is not being implemented in Covid-19 responses (UN Women, 2021a). National action plans (NAPs) have been delayed by the pandemic in Iraq, Nepal, Uganda, Afghanistan and Mali (UN 
Women, 2021a). In Bangladesh, UN Women is addressing the gendered aspect of Covid-19 related to security, law enforcement and local government (UN Women, 2021a).

\section{References}

Acosta, A. M., \& Evans, D. (2020). COVID-19 and Girls' Education: What We Know So Far and What We Expect. Center For Global Development. https://www.cgdev.org/blog/covid-19and-girls-education-what-we-know-so-far-and-what-we-expect-happen

Amaro, D., Pandolfelli, L., \& Sanchez-Tapia, I. (2020). COVID-19 and education: The digital gender divide among adolescents in sub-Saharan Africa. Evidence for Action. https://blogs.unicef.org/evidence-for-action/covid-19-and-education-the-digital-genderdivide-among-adolescents-in-sub-saharan-africa/

Australian Academy of Science. (2021). Impact of COVID-19 on women in the STEM workforce / Asia-Pacific. https://www.science.org.au/files/userfiles/support/documents/impact-covidwomen-stem-asia-pacific.pdf

Barrientos, S., \& Pallangyo, C. (2020). Building back equitably: Spotlight on Covid-19 and women workers in global value chains. Work and Opportunities for Women [WOW]. https://assets.publishing.service.gov.uk/government/uploads/system/uploads/attachment _data/file/925778/Building-back-equitably.pdf

Bourgault, S., Peterman, A., \& O’Donnell, M. (2021). Violence Against Women and Children During COVID-19-One Year On and 100 Papers In.

https://www.cgdev.org/sites/default/files/vawc-fourth-roundup.pdf

Chen, M., Grapsa, E., Ismail, G., \& Rogan, M. (2021). Distinct Pathways of Impact and Recovery in 11 Cities Around the World. Women in Informal Employment: Globalizing and Organizing (WIEGO).

https://www.wiego.org/sites/default/files/publications/file/WIEGO_Working\%20Paper\%20 No\%2042\%20May\%202021.pdf

Copley, A., Decker, A., Delavelle, F., Goldstein, M., O'Sullivan, M., \& Papineni, S. (2020). COVID-19 Pandemic Through a Gender Lens. World Bank, Washington, DC. https://doi.org/10.1596/34016

Crompton, Helen, Chigona, Agnes, Jordan, Katy, \& Myers, Christina. (2021). Inequalities in Girls' Learning Opportunities via EdTech: Addressing the Challenge of Covid-19. Zenodo. https://doi.org/10.5281/ZENODO.4917252

ILO. (2021). World Employment and Social Outlook Trends 2021.

https://www.ilo.org/wcmsp5/groups/public/---dgreports/---dcomm/--publ/documents/publication/wcms_795453.pdf

Jones, L. (2020). Women's representation and voice in media coverage of the coronavirus crisis. King's College London. https://www.kcl.ac.uk/giwl/assets/covid-media-analysis.pdf 
Kabeer, N., Razavi, S., \& van der Meulen Rodgers, Y. (2021). Feminist Economic Perspectives on the COVID-19 Pandemic. Feminist Economics, 27(1-2), 1-29.

https://doi.org/10.1080/13545701.2021.1876906

Kassova, L. (2021). The Missing Perspectives of Women in COVID-19 News. International Women's Media Foundation. https://www.iwmf.org/wpcontent/uploads/2020/09/2020.09.16-FULL-COVID-REPORT.pdf

Marshall, L., \& Moore, R. (2020, April 2). Access to digital learning during COVID-19 closures: Compounding educational inequality? The Education and Development Forum (UKFIET). https://www.ukfiet.org/2020/access-to-digital-learning-during-covid-19-closurescompounding-educational-inequality/

Meagher, K., Singh, N. S., \& Patel, P. (2020). The role of gender inclusive leadership during the COVID-19 pandemic to support vulnerable populations in conflict settings. BMJ Global Health, 5(9), e003760. https://doi.org/10.1136/bmjgh-2020-003760

Nieves, C. de P., Gaddis, I., \& Muller, M. (2021). Gender and COVID-19: What have we learnt, one year later? https://openknowledge.worldbank.org/bitstream/handle/10986/35829/Gender-andCOVID-19-What-have-we-learnt-one-year-later. pdf?sequence=1\&isAllowed=y

O'Donnell, M., Buvinic, M., Kenny, C., Bourgault, S., \& Yang, G. (2021). Promoting Women's Economic Empowerment in the COVID-19 Context. Center for Global Development. https://www.cgdev.org/sites/default/files/promoting-wee-during-covid.pdf

Piazza, K. S., \& Diaz, G. (2020). Light in the midst of chaos: COVID-19 and female political representation. World Development, 136, 105125.

https://doi.org/10.1016/j.worlddev.2020.105125

Rights of Women survey reveals online sexual harassment has increased, as women continue to suffer sexual harassment whilst working through the Covid-19 pandemic. (2021, January 11). Rights of Women. https://rightsofwomen.org.uk/news/rights-of-women-surveyreveals-online-sexual-harassment-has-increased-as-women-continue-to-suffer-sexualharassment-whilst-working-through-the-covid-19-pandemic/

Sanchez-Tapia, I., \& Alam, A. (2020). Towards an equal future: Reimagining girls' education through STEM. https://www.unicef.org/media/84046/file/Reimagining-girls-educationthrough-stem-2020.pdf

Strenio, J., \& Chowdhury, J. R. (2021). Remote work during COVID-19: Challenges and opportunities for combatting workplace sexual harassment | Feature from King's College London. https://www.kcl.ac.uk/remote-work-during-covid-19

The impact of COVID-19 on women scientists from developing countries: Results from an OWSD member survey | OWSD. (n.d.). Retrieved 6 August 2021, from https://owsd.net/news/news-events/impact-covid-19-women-scientists-developingcountries-results-owsd-member-survey 
UN Women. (2020). Online and ICT Facilitated Violence Against Women and Girls during COVID-19 (UN Women Ending Violence Against Women (EVAW) COVID-19 Briefs No. 4; UN Women Ending Violence Against Women (EVAW) COVID-19 Briefs, Vol. 4). https://doi.org/10.18356/b3f5cc80-en

UN Women. (2021a). Corporate evaluation of UN Women's support to national action plans on women, peace and security. https://www.unwomen.org//media/headquarters/attachments/sections/library/publications/2020/evaluation-unwomen-support-to-national-action-plans-en.pdf?la=en\&vs=4557

UN Women. (2021b). Sexual harassment against women with disabilities in the world of work and on campus. https://www.unwomen.org//media/headquarters/attachments/sections/library/publications/2020/discussion-papersexual-harassment-against-women-with-disabilities-en.pdf?la=en\&vs=1256

UNESCO. (2021). To be smart, the digital revolution will need to be inclusive. https://unesdoc.unesco.org/ark:/48223/pf0000375429. locale=en. page=4

UNICEF. (2020). Protecting Children from Violence in the Time of COVID-19: Disruptions in prevention and response services. https://www.unicef.org/media/74146/file/Protectingchildren-from-violence-in-the-time-of-covid-19.pdf

Woolston, C. (2020). 'It's like we're going back 30 years': How the coronavirus is gutting diversity in science. Nature. https://doi.org/10.1038/d41586-020-02288-3

WTO. (2020). The Economic Impact of COVID-19 on Women in Vulnerable Sectors and Economies (Covid-19 Reports No. 2020/10; Covid-19 Reports, Vol. 2020/10). https://doi.org/10.30875/74a82a3d-en

\section{Key websites}

- UN COVID-19 Global Gender Response Tracker: https://data.undp.org/gendertracker/

- UN COVID-19 and gender monitor: https://data.unwomen.org/resources/covid-19-andgender-monitor

- Studies of Covid-19 \& Violence Against Women \& Children: A Global Tracker: https://docs.google.com/spreadsheets/d/1w28pmDt-IOlcl9cvaUdAMVVDzftOil1/edit\#gid=269101278

- Gender and Covid-19: https://www.genderandcovid-19.org/gender-working-group-page/ 


\section{Acknowledgements}

We thank the following experts who voluntarily provided suggestions for relevant literature or other advice to the author to support the preparation of this report. The content of the report does not necessarily reflect the opinions of any of the experts consulted.

- $\quad$ Carmen de Paz Nieves, World Bank

- Shelby Bourgault, Center for Global Development

- Kristen Meagher, King's College London

\section{Suggested citation}

Kelly, L. (2021). Direct and indirect impacts of the COVID-19 pandemic on women and girls. K4D Helpdesk Report. Institute of Development Studies. DOI 10.19088/K4D.2021.141

\section{About this report}

This report is based on six days of desk-based research. The K4D research helpdesk provides rapid syntheses of a selection of recent relevant literature and international expert thinking in response to specific questions relating to international development. For any enquiries, contact helpdesk@k4d.info.

K4D services are provided by a consortium of leading organisations working in international development, led by the Institute of Development Studies (IDS), with the Education Development Trust, Itad, University of Leeds Nuffield Centre for International Health and Development, Liverpool School of Tropical Medicine (LSTM), University of Birmingham International Development Department (IDD) and the University of Manchester Humanitarian and Conflict Response Institute (HCRI).

This report was prepared for the UK Government's Foreign, Commonwealth \& Development Office (FCDO) and its partners in support of pro-poor programmes. Except where otherwise stated, it is licensed for non-commercial purposes under the terms of the Open Government Licence v3.0. K4D cannot be held responsible for errors or any consequences arising from the use of information contained in this report. Any views and opinions expressed do not necessarily reflect those of FCDO, K4D or any other contributing organisation.

(C) Crown copyright 2021.

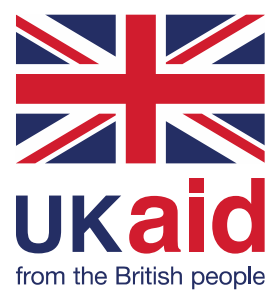

